\title{
LÍNGUA PORTUGUESA EM UM CONTEXTO MULTILÍNGUE: DESAFIOS PARA O SEU ENSINO ${ }^{1}$
}

\author{
PORTUGUESE LANGUAGE IN A MULTILINGUAL CONTEXT: CHALLENGES FOR \\ THE EDUCATION
}

Angélica Ilha Gonçalves ${ }^{2}$

\begin{abstract}
Resumo
Este trabalho teve por objetivo investigar os principais desafios para a interação durante o ensino de língua portuguesa em Timor-Leste, enfrentados por professores brasileiros, e investigar as formas encontradas por esses docentes para auxiliar seus alunos durante a aprendizagem. Para o estudo, foram consideradas as particularidades do contexto histórico timorense (ALMEIDA, 2011), as peculiaridades do ensino de língua portuguesa em Timor (BRITO, 2010) e a importância da interação durante o processo de ensino-aprendizagem de uma língua (VYGOTSKY, 1998). Participaram da pesquisa quatro professores que, pela primeira vez, estavam atuando no país em cursos de nível básico de língua portuguesa. Através das entrevistas realizadas, foi possível perceber que os desafios superavam as questões sobre a forma de ensino e o conteúdo, abrangendo discussões sobre por que aprender a língua no país, como despertar o interesse e como garantir o envolvimento dos(as) alunos(as) nos cursos.
\end{abstract}

Palavras-chave: Interação. Língua Portuguesa. Timor-Leste.

\begin{abstract}
This study aimed to investigate the main challenges for interaction during the Portuguese language teaching in East Timor faced by Brazilian teachers, and also investigating the ways found by those teachers to help their students during the learning process. For the study, the characteristics considered were the timorese historical context (ALMEIDA, 2011), the peculiarities of the Portuguese language teaching in Timor (BRITO, 2010) and the importance of interaction in the process of teaching and learning a language (VYGOTSKY, 1998). The research participants consisted of four teachers who, for the first time, were teaching in the country at a basic level of Portuguese language courses. Through the interviews, it was revealed that the challenges overcame questionings about the way of teaching and content, covering discussions such why learning the language in the country, how to awake the interest and how to ensure the involvement of the students in the courses.
\end{abstract}

Keywords: Interaction. Portuguese Lenguage. Est Timor.

\footnotetext{
${ }^{1}$ Este artigo foi realizado com autorização do PQLP e apoio da Capes.

${ }^{2}$ A autora é Mestra em Letras: Estudos Linguísticos, pelo Programa de Pós-Graduação em Letras da UFSM. Atuou como professora tutora e formadora no curso de Letras Espanhol EaD/UAB/UFSM, lecionou no Curso de Espanhol para Viagens do Centro de Ensino e Pesquisa de Línguas Estrangeiras Instrumentais (Cepesli) e no Programa de Qualificação de Docentes e Língua Portuguesa, em Timor-Leste. Atualmente, é professora estadual, lecionando a disciplina de Língua Espanhola no ensino médio e participa de grupos de estudos sobre português e espanhol como línguas estrangeiras no Cepesli/UFSM. E-mail: angelllig@ yahoo.com.br
} 


\section{CONSIDERAÇÕES INICIAIS}

O contexto de ensino-aprendizagem de línguas em Timor-Leste é, no mínimo, instigante. Em um país que possui duas línguas oficiais (Tétum e Português), duas línguas de trabalho (Bahasa-Indonésia e Inglês) e cerca de dezesseis línguas nacionais, as questões linguísticas se sobressaem aos olhos de qualquer professor. Especificamente para os professores de língua portuguesa, mais do que instigante, é certamente desafiante, especialmente pelo percurso histórico dessa língua no país.

Desde o início do processo de colonização de Timor-Leste, Portugal não se preocupou com a realização de uma expansão linguístico-cultural, havendo uma difusão "tímida" da língua, realizada principalmente pelas missões religiosas. Se desde o século XVI não houve uma maior disseminação da língua, foi com a invasão indonésia em 1975 que a problemática se intensificou, já que o seu uso foi proibido.

A partir de 2002, com a restauração da independência e a escolha da língua portuguesa como uma de suas línguas oficiais, o país passou a viver um novo momento histórico do processo de ensino-aprendizagem dessa língua. Foi em meio a esse cenário que professores estrangeiros voltaram a atuar mais efetivamente no país para propagar o ensino da língua portuguesa, agora através de programas de cooperação.

Com a intenção de colaborar para a reestruturação de Timor, a Agência Brasileira de Cooperação (ABC) realizou no ano de 2000 uma missão para verificar as possíveis áreas de atuação. Foi nesse ano que iniciaram os projetos de cooperação entre os países sendo o primeiro deles a implementação do Centro de Promoção Social, Formação Profissional e Desenvolvimento Empresarial Becora, em parceria com o Serviço Nacional de Aprendizagem Industrial (SENAI). ${ }^{3}$

Além da área técnica, o governo brasileiro também se preocupou em desenvolver projetos voltados para a formação de professores e ensino de língua portuguesa. Esse foi o caso do Programa de Qualificação de Docente e Ensino de Língua Portuguesa no TimorLeste (PQLP), criado em 2004, por meio do Decreto $\mathrm{n}^{\circ}$ 5.274. Esse Programa tem por objetivo "[...] a execução do ensino da língua portuguesa e outras atividades relacionadas à formação de docentes de diversos níveis das instituições de ensino timorenses". (CAPES, 2013, p. 01).

\footnotetext{
${ }^{3}$ Para maiores esclarecimentos, consultar: http://www.abc.gov.br/Projetos/CooperacaoSulSul/TimorLeste.
} 
Tendo em vista essa finalidade, o Programa selecionou entre os anos de 2004 e 2013 grupos de professores para atuar em cooperação educacional, sendo que uma das áreas de atuação desses profissionais era o fomento ao ensino de língua portuguesa. Em $2014^{4}$, dentre os doze professores da área de Letras selecionados, nove nunca estiveram no país, deparandose pela primeira vez com esse contexto de ensino-aprendizagem, em que vigora a diversidade linguística.

Essa diversidade encontrada na capital Díli, local de atuação desses professores, é um fator a ser considerado durante a elaboração de materiais e estratégias de ensino, pois além das línguas oficiais (Tétum e Português) e das línguas de trabalho (Bahasa-Indonésia e Inglês), evidencia-se a presença das línguas nacionais e outras línguas estrangeiras como Espanhol, Francês e Mandarim. Além disso, é preciso ter em vista que a grande maioria da população jovem entre 15 e 24 não fala português, mas sim tétum (77,8\%) (CENSO, 2010). No entanto, esse não é o idioma dominado pelos novos professores brasileiros que foram atuar no país.

Nesse caso, a interação para o ensino-aprendizagem de língua portuguesa, como língua não materna ${ }^{5}$, é uma das problemáticas enfrentadas por professores e alunos. É nesse sentido que este trabalho busca investigar os principais desafios para a interação durante o ensino de língua portuguesa em Timor-Leste, enfrentados por professores brasileiros, e investigar as formas encontradas por esses docentes para auxiliar seus alunos durante a aprendizagem.

Para tanto, as seções seguintes contemplam: breve contextualização histórica de Timor-Leste, o percurso da língua portuguesa nesse país e a importância da interação para o processo de ensino-aprendizagem de uma língua. Por se tratar de um artigo, foram considerados apenas alguns dos fatores mais relevantes, embora entenda-se que séculos de história não devam ser menosprezados.

\footnotetext{
${ }^{4}$ Edital 76/2013, disponível em: <http://www.capes.gov.br/cooperacao-internacional/timor-leste/programa-dequalificacao-de-docente-e-ensino-de-lingua-portuguesa-no-timor-leste>.

${ }^{5}$ Por considerar que não há um consenso entre os autores sobre a língua portuguesa ensinada em Timor-Leste (língua estrangeira, segunda língua, língua adicional) e que a prática dos professores pode levar diferentes visões sobre essa língua, optou-se por adotar a nomenclatura "português língua não materna", pois os dados do Censo de 2010 e a experiência profissional possibilitaram evidenciar que o seu ensino não é de língua materna, mas pode ser relacionado às demais concepções de língua.
} 


\section{CONTEXTO HISTÓRICO E A LÍNGUA PORTUGUESA}

Situado entre a Austrália, ao sul, e o arquipélago Indonésio, ao norte, Timor-Leste encontra-se entre aproximadamente 17.000 ilhas do Sudeste Asiático, apresenta cerca de $15.000 \mathrm{~km}^{2}$ de extensão, possui 13 distritos, 65 subdistritos e 442 sucos (TIMOR-LESTE, 2013). Constituído pela metade oriental da ilha de Timor, o ilhéu de Jaco (extremo leste), a ilha de Ataúro (costa norte de Díli) e o enclave de Oecussi-Ambeno (costa norte da parte indonésia da Ilha de Timor), possui uma população com pouco mais de 1 milhão de habitantes. (TIMOR-LESTE, 2014).

A República Democrática de Timor-Leste nasceu efetivamente, ao menos enquanto país com independência restaurada, em 20 de maio de 2002. Sendo um dos países mais jovens do mundo, a sua história é marcada por conflitos, invasões, domínio estrangeiro e luta e resistência de seu povo.

Durante quatro séculos, o país foi colônia de Portugal, passou por um período de ocupação japonesa na Segunda Guerra Mundial e foi invadido pela Indonésia em 1975, ocupação que durou 24 anos. Foi apenas em 1999, após esse longo período de resistência à ocupação indonésia, que a população timorense votou pela restauração da independência em um referendo realizado em 30 de agosto de 1999.

Embora mais de $90 \%$ da população tenha participado do referendo e $78,5 \%$ tenha votado pela independência formal, a milícia pró-indonésia continuou a atuar no país e insatisfeita com o resultado, executou timorenses, atacou funcionários representantes das Nações Unidas e incendiou casas (BRITO, 2010). Para reestabelecer a paz e garantir a reconstrução do país, foi instaurada uma administração transitória até 2002 (UNTAET United Nations Transitory Administration East Timor), chefiada pelo brasileiro Sérgio Vieira de Mello. (BRITO, 2010).

É em meio a esse cenário que a língua portuguesa foi, em alguns momentos, pouco incentivada, em outros completamente proibida e, atualmente, encontra-se em um período de fomento. É oportuno considerar ainda, que se antes de 1975, o ensino de português era destinado a algumas minorias, após a invasão indonésia, passou a ser associado à implementação da democracia (ALMEIDA, 2011) ou ainda de um projeto político de independência da Indonésia.

Mas a escolha da língua portuguesa como língua oficial também foi motivada por 
outros fatores, sendo necessária a compreensão da sua influência histórica. Por essa razão, a próxima seção tratará especificamente da presença da língua portuguesa em Timor-Leste.

\section{A LÍNGUA PORTUGUESA EM TIMOR-LESTE}

Desde o século XVI, com a chegada dos portugueses em Timor-Leste, a língua portuguesa foi utilizada para os primeiros contatos com a população local. Esses contatos tiveram por finalidade o estabelecimento de relações comerciais e a evangelização. Em 1702, a língua portuguesa ganhou um maior significado político com a chegada do primeiro Governador de Timor. (ALMEIDA, 2011).

No século XIX, foram criadas escolas de cunho religioso por missionários portugueses, mas foi apenas na década de 1960 que houve maior empenho para alfabetizar a população em língua portuguesa, com a criação de escolas por todo o território (ALMEIDA, 2011). Entretanto, os quatro séculos de domínio português não foram profícuos para o ensino dessa língua que, segundo Brito (2010), nunca chegou a ser a língua de contato entre as etnias diferentes ou de comunicação oral, papel desempenhado pelo tétum.

Se, por um lado, o longo período de colonização portuguesa em quase nada contribuiu para o desenvolvimento dessa região; por outro lado, a língua portuguesa e a religião católica foram formadoras de uma determinada cultura, cujas marcas se misturaram com as culturas nativas, de influência chinesa e malaia, que remontam ao século XIII, atraídas pela exploração de sândalo, hoje extinta. (ALMEIDA, 2011, p. 22).

No entanto, com a invasão indonésia em 1975, a língua portuguesa passou a assumir um outro papel, o de língua de resistência. Forçados a aprender a língua indonésia, o português foi valorizado como um "elemento ancestral e integrado na cultura nacional" (HULL, s.d, p. 37).

Sendo proibido o uso da língua portuguesa, o que poderia significar a morte, TimorLeste passou por um período denominado por Brito (2010) de "destimorização", caracterizado pela proibição da expressão em língua portuguesa, pela minimização da língua tétum e pelo ensino da variante do malaio - bahasa indonésia. Diante da tentativa indonésia de eliminar as interferências portuguesas, a língua portuguesa passou a representar um fator de unidade nacional contra o invasor. (ALMEIDA, 2011),

Se por um lado a política repressiva da Indonésia prejudicou o uso da língua 
portuguesa, por outro beneficiou o tétum, pois a Igreja Católica passou a utilizá-lo como língua litúrgica (HULL, s.d). A adoção do tétum pela Igreja permitiu uma rápida propagação dessa língua e sua efetiva utilização pela população, sendo hoje uma língua integradora das demais línguas nacionais.

As línguas originais do país, pertencentes à família das línguas austronésias (ou malaio-polinésicas) ou à família das línguas papuas (ou indo-pacíficas), utilizadas nas diversas localidades do país, assumiram o tétum como o seu veículo de integração (BRITO, 2010). Embora o tétum tenha garantido seu lugar na sociedade timorense, após o referendo de 1999, o português emergiu a partir das decisões políticas sobre as línguas oficiais do país. A sua escolha ocorreu por diferentes razões, sendo algumas:

[...] para a apropriação por parte dos timorenses, da língua portuguesa como fator de identidade cultural, contribuíram vários fatores [...]:

- A atuação da Igreja na aproximação às raízes culturais do povo e o seu papel na difusão da língua portuguesa e na formação.

- A duração do domínio português (quatro séculos e meio) e a construção de uma memória coletiva.

- A comparação entre o caráter violento das invasões protagonizadas por outras nações (primeiro o Japão, durante a Segunda Guerra Mundial, e depois a Indonésia) e a administração mais moderada do território praticada pelos portugueses.

- A associação do português ao movimento da resistência e ao consequente despertar de uma unidade nacional, funcionando como uma arma de luta cultural. (BRITO, 2011, p. 28).

Hoje, embora o tétum funcione como uma língua franca, ainda não permite a comunicação internacional. Nesse caso, é o português que passa a assumir esse papel, porém não é a língua falada pela maioria da população. O censo realizado em 2010 , com jovens de idade entre 15 e 24 anos identificou que 39,3\% dessa população era alfabetizada em português.

Esse número é superior ao de 2004 em que apenas 17,2\% era alfabetizada nessa língua. Os dados mostram também um crescimento na alfabetização em inglês $(22,3 \%$ em 2010 e 10\% em 2004) e uma diminuição na língua indonésia (55,6\% em 2010 e 66,8\% em 2004).

Nesse mesmo ano, Brito escreveu sobre a segmentação dos usos das línguas de acordo com a situação comunicativa em que os timorenses se deparavam. Em seu relato, a autora descreve situações facilmente encontradas atualmente: 
Por exemplo, na escola ministra-se a norma do português europeu; em casa, fala-se o tétum; entre os alunos adolescentes utiliza-se a bahasa indonésia. Presenciou-se situação de diglossia entre adultos que participavam de um curso de capacitação de professores: conosco procuravam expressar- se em português; quando dialogavam com indivíduos vindos do seu Suco, utilizavam a língua local; quando de origens diversas, conversavam em tétum ou bahasa indonésia (observou-se que poucas vezes o português era utilizado em tais circunstâncias. (BRITO, 2010, p. 182).

Embora o censo de 2010 revele um crescimento da alfabetização em língua portuguesa, o que pode ser comprovado com os diversos cursos oferecidos no país para professores, alunos e funcionários públicos, observa-se a pouca utilização da língua no dia a dia dos timorenses. Ainda que esta seja uma observação empírica, é notável a dificuldade de comunicação em situações práticas do cotidiano, como pedir informações, compras de produtos em uma loja ou mesmo ir a um restaurante.

Nesses momentos e naqueles que ocorrem em sala de aula são nítidos os desafios para a interação, que requer uma troca entre os sujeitos. Para refletir mais sobre essa questão, a próxima seção aborda a importância da interação durante o processo de ensino-aprendizagem.

\section{IMPORTÂNCIA DA INTERAÇÃO PARA A APRENDIZAGEM}

Em uma visão interacionista da aprendizagem, o sujeito se constitui nas e pelas interações sociais, ou seja, não é um ser meramente passivo, mas sim construído por fatores sociais e históricos, os quais também transforma. No século XX, Vygotsky (1998) já tratava da importância do outro durante o processo de aprendizagem, pois considerava que as trocas recíprocas entre os sujeitos garantiriam o desenvolvimento e, consequentemente, a aprendizagem.

Essas trocas são entendidas por Morato (2004) como uma "ação partilhada" de forma reflexiva, isto é, interação. Dessa forma, quando se fala em aprendizagem de uma língua é preciso considerar que esta ocorre através das trocas recíprocas entre os sujeitos e não isoladamente. Especificamente em ambientes formais de ensino, a interação ocorre entre professor-alunos e alunos-alunos.

No entanto, Coracini (2005) propõe uma ampliação desse outro, podendo ser um livro, um filme ou uma música, não se restringindo unicamente a uma pessoa. Nesse caso, pode-se dizer que há uma interação baseada na negociação, na troca de ideias e outra que ocorre de forma linear, sem essa reciprocidade. A primeira é denominada por Primo (2003) como "interação mútua" e a segunda, como "interação reativa". 
O conceito de interação mútua e reativa, permite distinguir ao menos três tipos de interação que ocorre em sala de aula. Tais tipos de interação são apresentados por Moore e Kearsley (2011) como:

a) Interação aluno-conteúdo: corresponde ao aprendizado do conteúdo e ao planejamento de como estudá-lo.

b) Interação aluno-aluno: diz respeito àquela que ocorre com um grupo de alunos ou entre grupos de alunos.

c) Interação aluno-professor: àquela em que o professor auxilia o aluno em sua aprendizagem.

Esses três tipos de interação são fundamentais para a aprendizagem de uma língua e precisam ser considerados durante o processo de ensino-aprendizagem. Entretanto, a complexidade de garantir a interação para a aprendizagem de uma língua é ampliada quando o professor não domina a(s) língua(s) materna(s) de seu aluno. Esse desafio torna-se ainda maior em um contexto de plurilinguismo, como é o caso de Timor-Leste.

Diante desse contexto, cabe refletir sobre a escolha de abordagens e de procedimentos mais apropriados para cada situação de aprendizagem ou, ainda, “[...] não se pode falar de uma metodologia específica" (BELTRÁN; 2005, p. 1123), pois dependerá da necessidade do aluno. É nesse sentido que surge o desafio de como possibilitar a interação para a aprendizagem da língua portuguesa, como língua não materna, considerando as peculiaridades do processo de ensino-aprendizagem em Timor-Leste.

\section{APRESENTAÇÃO DA PESQUISA E DOS PARTICIPANTES}

O desenvolvimento do estágio docente pelo Programa de Qualificação Docente e Ensino de Língua Portuguesa no Timor-Leste (PQLP/CAPES), tem possibilitado aos professores brasileiros selecionados o contato com uma realidade educativa diferente, haja vista o quadro histórico relatado. Foram tais experiências que despertaram o interesse em desenvolver esta pesquisa, já que a autora foi uma das professoras selecionadas para atuar em Timor-Leste no ano de 2014.

Em poucos meses de trabalho, foi possível observar a existência de diferentes desafios. Um deles encontra-se no fato da grande maioria da população não falar português e a autora não falar tétum, o que dificultava a interação, embora não a impossibilitasse. $O$ que foi 
igualmente verificado nos cursos considerados de nível básico ${ }^{6}$ ofertados em diferentes instituições de Timor-Leste pelos professores brasileiros.

Por acreditar que esses desafios fossem mais sobressalientes aos professores que atuavam pela primeira vez no país, essa pesquisa foi desenvolvida apenas com os novos professores selecionados pelo programa ${ }^{7}$. Nesse caso, foi considerado que estes ainda estavam em um processo de adaptação às diversas situações. Por outro lado, os professores que já estavam há mais tempo, encontraram formas de agir e trabalhar nesse contexto, que ainda estavam sendo descobertas pelos que chegaram posteriormente.

Dos nove professores que começaram a atuar pela primeira vez no país a partir de maio de 2014, cinco deles trabalharam com cursos em nível básico. Como um desses professores é a autora, a pesquisa foi realizada com quatro professores, os demais não foram investigados por atuarem com disciplinas de literatura, outras disciplinas da área de Letras ou com língua portuguesa em nível intermediário ou avançado.

O intuito em manter o foco nos professores dos cursos de nível básico ocorreu por acreditar-se que os desafios encontrados por esses profissionais eram diferentes daqueles identificados nos níveis intermediário e avançado, em que os alunos já possuíam um conhecimento maior de língua portuguesa.

A realização dessa pesquisa foi constituída de duas partes, a primeira com a aplicação de um questionário para traçar o perfil dos professores e a segunda com o desenvolvimento de uma entrevista semiestruturada. O objetivo da entrevista foi identificar os principais desafios que esses professores enfrentaram ao ministrar cursos de língua portuguesa em nível básico.

Com o objetivo de preservar a identidade dos professores, nesta pesquisa foi utilizada a denominação A, B, C e D sem identificação de gênero. A seguir é apresentado um breve perfil de cada um deles:

1) Professor A: era graduado em Letras Português e mestrando em Linguística (linha de pesquisa: Políticas Linguísticas). Atuava há quatro como professor, tendo trabalhado em cursos de idiomas e tinha experiência com ensino de português como língua não materna. Essa experiência advinha de cursos de português para estrangeiros ministrados em uma universidade brasileira, de voluntariado realizado na Embaixada do Brasil em Tirana/Albânia

\footnotetext{
${ }^{6}$ A designação "nível básico" para os cursos de língua portuguesa é utilizada pelo Programa a partir de testes de nivelamento que são realizados com os alunos, em que é necessário atingir uma determinada pontuação em provas escritas e orais.

${ }^{7}$ Esses professores realizaram a seleção do ano de 2013, sendo esta a última seleção realizada pelo Programa, e aturam em Timor-Leste entre 2014 e 2016.
} 
e do ensino de português para intercambistas.

2) Professor B: era graduado em Letras Português e mestre em Educação. Atuava há cinco anos como professor, tendo experiência com ensino fundamental, médio e educação de jovens e adultos. Antes de participar do programa, não tinha experiência com ensino de português como língua não materna.

3) Professor C: era graduado em Letras Português e Inglês, Sistemas de Informação e mestre em Linguística (linha de pesquisa: Linguagem Humana e Tecnologia). Possuía quatro anos de experiência como professor em cursos de idiomas e experiência com ensino de português como língua não materna, tendo atuado com ensino de língua portuguesa para noruegueses e cubanos.

4) Professor D: era graduado em Letras Português, licenciatura e bacharelado e mestre em Língua Portuguesa (linha de pesquisa: Fonética Acústica e Fonologia). Tinha experiência de três anos como professor, tendo atuado com ensino médio, cursos preparatórios para concursos e vestibular. Antes de participar do programa, não tinha experiência com ensino de português como língua não materna.

Com as respostas obtidas através do questionário e da entrevista, a análise dos dados foi realizada a partir do processo de leitura e releitura (LÜDKE; ANDRÉ, 1986). Assim, os dados foram divididos em três categorias: desafios para a interação e ensino de língua portuguesa, estratégias para lidar com os desafios e sugestões para outros professores.

Na seção seguinte, é feita a apresentação e a discussão desses dados. Cabe esclarecer que, para as transcrições das falas dos professores, foram utilizadas algumas convenções adaptadas de Koch (2006) ${ }^{8}$.

\section{APRESENTAÇÃO E DISCUSSÃO DOS DADOS}

No momento da realização dessa pesquisa, os professores participantes estavam há seis meses trabalhando em Timor-Leste. Todos chegaram em maio de 2014 e já haviam finalizado seus cursos de português, como língua não materna, em nível básico. Tais cursos apresentavam uma carga horário de $60 \mathrm{~h}$ e foram desenvolvidos em universidades privadas de Timor-Leste.

\footnotetext{
${ }^{8}$ MAIÚSCULAS (Entoação enfática.) - ? (Interrogação.) - ! (Forte ênfase ao que está sendo dito.) - (Pequena pausa.) - "” (Citações literais ou reproduções de discurso direto.) - [...] (Supressões.) - Ah, éh, ahn, tá (Elementos fáticos).
} 
Com exceção do professor A, que ministrou o curso para professores e funcionários de uma dessas universidades, os demais tiveram como grupo de alunos apenas professores de diferentes cursos e disciplinas. A idade e o número de alunos variaram em cada uma das turmas, conforme pode ser verificado no quadro 1.

No quadro 1, observa-se que o número de alunos que concluíram os cursos decaiu em relação ao número de alunos que o iniciaram. Essa observação aparece nas entrevistas como uma das reflexões dos professores sobre o grau de interesse dos discentes pela língua portuguesa.

Quadro 1 - Idade e número de alunos por professor

\begin{tabular}{|l|l|l|l|}
\hline & $\begin{array}{c}\text { Número inicial de } \\
\text { alunos }\end{array}$ & Alunos concluintes & Idade dos alunos \\
\hline Professor A & 27 & 14 & Entre 25 e 35 anos \\
\hline Professor B & 22 & 16 & Entre 23 e 45 anos \\
\hline Professor C & 35 & 19 & Entre 24 e 60 anos \\
\hline Professor D & 37 & 27 & Entre 30 e 50 anos \\
\hline
\end{tabular}

Fonte: Autoria própria.

Antes de iniciarem suas atividades nos respectivos cursos, todos os professores realizaram um curso intensivo de tétum, oferecido pelo PQLP. Esse curso foi desenvolvido durante uma semana, com aulas teóricas pela manhã e atividades de imersão no período da tarde, sempre com o apoio de professores timorenses.

Assim, ao serem indagados sobre como avaliavam o conhecimento dessa língua ao iniciarem suas atividades docentes no país, todos os professores consideraram que ainda tinham pouco conhecimento e que o que sabiam era decorrente da participação nesse curso intensivo.

Os professores também foram questionados sobre o conhecimento que tinham das línguas faladas no país antes de iniciarem as atividades em Timor-Leste. Nesse caso, os professores A e D responderam que haviam pesquisado antes de chegarem ao país, já os professores B e C afirmaram não ter nenhuma informação sobre o assunto. Essas respostas foram obtidas através do questionário e demonstram a necessidade de maiores informações antes da chegada ao país, pois essa também é uma maneira de preparar os professores para a 
atuação.

$\mathrm{Na}$ entrevista, foi solicitado que os professores fizessem uma avaliação de suas aulas, identificassem quais as dificuldades que enfrentaram, como lidaram com essas dificuldades, como agiram quando os alunos não compreendiam o que falavam, quais seriam os principais desafios para se ensinar português em contexto timorense e quais as sugestões de como lidar com esses desafios.

Ao iniciar a pesquisa, acreditava-se que o grande desafio para a interação em sala de aula, ao se ensinar português em nível básico, seria o fato dos professores não terem conhecimento de língua tétum que possibilitasse a comunicação, já que essa é a língua de integração do país, ou seja, a língua franca (BRITO, 2010). Entretanto, observou-se que esta não era a principal dificuldade e que outras questões preocupavam mais os professores.

Durante a entrevista, os quatro professores disseram acreditar que ter conhecimento do tétum era importante para o ensino de português em contexto timorense, mas não fundamental, o que pôde ser verificado nos excertos 1, 2, 3 e 4. A importância estaria no fato de ser possível fazer associações entre as línguas, reconhecer a origem das dificuldades dos alunos e facilitar o entendimento das explicações, quando o professor não encontrasse outra forma de fazê-lo sem utilizar a língua falada pelo aluno.

P': Qual a importância do conhecimento de tétum para o ensino de língua portuguesa?

[1]

A: $[\ldots]$ eu tento fazer o contraste entre o português e o tétum na sala de aula. Então por exemplo, quando eu vou falar de preposição, de flexão verbal, como isso eu tenho alguma noção do tétum, eu uso essas minhas pequenas noções pra falar "ah em tétum óh como que a gente usa tal frase pra pessoa?" e tal, tal, tal, óh em português, aí eu faço o contraste, em português não é assim. Isso assim, dá um bom resultado $[\ldots]$.

[2]

B: Eu acho que sim, eu acho que auxilia muito, mas não diria fundamental.

[3]

C: [...] você consegue ensinar com certeza sem saber tétum, mas acho que influencia. É muito importante, até porque você sabe onde que ele vai ter a dificuldade 'ah não existe essa estrutura' $[\ldots]$.

[4]

D: [...] eu acho que a gente deve evitar ficar traduzindo muito, mas às vezes é inevitável assim, às vezes é muito difícil você não recorrer ao tétum ou à língua do seu aluno, principalmente no nível básico. E eu acho também o seguinte, mesmo que você não use a língua na sala de aula, porque, enfim, mesmo que você considere prejudicial pro ensino, "não, não devemos usar outras línguas em sala de aula", ainda assim é interessante você conhecer a língua do aluno pra você fazer associações com determinadas estruturas da língua, que você já sabe como que é, até os erros deles você já sabe, consegue identificar melhor $[\ldots]$.

\footnotetext{
${ }^{9}$ A letra "P" foi utilizada para identificar a pesquisadora. 
Os professores relataram, ainda, que quando não havia entendimento por parte de algum aluno, eles conseguiam encontrar formas de auxiliá-lo, sem que a interação fosse impossibilitada. Pelo quadro 2, percebe-se que todos os professores se utilizaram da interação aluno-aluno (MOORE; KEARSLEY, 2011) nos momentos em que não conseguiam explicar algo da língua portuguesa. Nesse caso, os alunos que tinham maior conhecimento ajudavam seus colegas explicando em língua tétum, facilitando a chamada "interação mútua" (PRIMO, 2003), em que a reciprocidade é o foco.

Outra forma encontrada pelos professores A, C e D foi utilizar o inglês, já que consideravam que muitos de seus alunos tinham conhecimento dessa língua. No entanto, os professores disseram ter utilizado minimamente este recurso, procurando outras formas como diferentes exemplos, mímicas, desenhos, uso de objetos e imagens.

\section{Quadro 2 - Formas encontradas pelos professores para garantir a interação}

\begin{tabular}{|l|l|}
\hline \multicolumn{1}{|c|}{ Professores } & \multicolumn{1}{c|}{ Ações para garantir a interação } \\
\hline A, B, C e D & Solicitou ajuda de alunos que tinham mais conhecimento de português. \\
\hline A, C e D & $\begin{array}{l}\text { - Usou o inglês em algum momento. } \\
\text { - Usou o que conhecia da língua tétum. }\end{array}$ \\
\hline B e D & $\begin{array}{l}\text { - Usou exemplos em determinados contextos. } \\
\text { - Utilizou imagem para representar palavras. }\end{array}$ \\
\hline C e D & Usou mímica. \\
\hline B & $\begin{array}{l}\text { - Explicou de formas diferentes. } \\
\text { - Utilizou sinônimos. }\end{array}$ \\
\hline C & Utilizou objetos para representar palavras. \\
\hline D & Fez desenhos para representar palavras. \\
\hline
\end{tabular}

Fonte: autoria própria.

Dessa forma, pode-se dizer que saber a língua do aluno facilita para o professor a interação mútua ou recíproca, mas não é visto como o mais importante. Cabe esclarecer, que os professores reconheram que seus alunos tinham algum conhecimento da língua portuguesa, embora estivessem no nível básico. Nesse caso, é preciso considerar que na história de TimorLeste houve períodos de maior e menor ensino da língua e que, durante a ocupação indonésia, a língua portuguesa foi associada à resistência, permanecendo no país de alguma forma (ALMEIDA, 2011) e, posteriormente, sendo retomada por questões políticas, sociais e pelas contribuições históricas. 
Foi nesse período de ocupação indonésia que os alunos com mais de 35 anos fizeram os seus cursos de graduação, em um momento em que o português havia sido proibido. Por outro lado, os alunos na faixa etária dos 20 anos graduaram-se quando a língua portuguesa já havia assumido o caráter de oficial e quando o país voltava a incentivar o seu uso.

Esse contexto precisa ser considerado para que se possa entender a preocupação dos participantes dessa pesquisa com o interesse de seus alunos pela língua portuguesa. Essa é a grande problemática identificada pelos quatro professores, que dificultaria o ensino de português e geraria problemas para a interação. No entanto, a interação entendida por esses professores não corresponde àquela estabelecida de forma recíproca entre os participantes (MORATO, 2004) ou à influência do outro no processo de ensino-aprendizagem (VYGOTSKY, 1998), mas sim relacionada às questões de interesse e motivação por parte dos alunos. O quadro 3, apresenta os demais desafios identificados pelos professores.

\section{Quadro 3 - desafios para o ensino de língua portuguesa em nível básico.}

\begin{tabular}{|c|c|}
\hline Professores & Desafios \\
\hline $\mathrm{A}, \mathrm{B}, \mathrm{C}$ e D & $\begin{array}{l}\text { A língua portuguesa não é de interesse dos alunos, falta descobrir qual a } \\
\text { necessidade da língua para os discentes. }\end{array}$ \\
\hline A, B, C e D & $\begin{array}{l}\text { Comportamento do aluno em sala de aula: dispersão, faltas, chegam } \\
\text { atrasados, não demonstram envolvimento com o processo de ensino- } \\
\text { aprendizagem. }\end{array}$ \\
\hline$A, B$ e $D$ & $\begin{array}{l}\text { A língua portuguesa é vista pelos alunos como muito difícil de ser } \\
\text { aprendida. }\end{array}$ \\
\hline A, C e D & $\begin{array}{l}\text { - Dificuldade de assimilação dos conteúdos. A aprendizagem é } \\
\text { considerada lenta. } \\
\text { - Falta uma rotina de estudo em casa e fazer as atividades extra-classe } \\
\text { solicitadas. }\end{array}$ \\
\hline A e B & $\begin{array}{l}\text { A aprendizagem da língua portuguesa é vista como obrigatória, já que é } \\
\text { a instituição em que os alunos trabalham que oferta o curso. }\end{array}$ \\
\hline A e C & Dispersão gerada pelo curso ser no mesmo local de trabalho. \\
\hline A e D & Alunos têm uma visão tradicional do ensino. \\
\hline
\end{tabular}

Fonte: Autoria própria.

Os professores acreditavam que havia um certo desinteresse pela aprendizagem do português, pois, aparentemente, não era algo importante para todos os alunos, o que pôde ser identificado claramente nos excertos 5 e 6. Cabe observar que como esses alunos eram professores, eles teriam que ensinar suas disciplinas em língua portuguesa, o que ainda não 
era obrigatório, mas sim indicado pelo governo timorense.

Por essa razão, para os professores A, B, C e D, faltava descobrir qual a real necessidade da aprendizagem da língua para os alunos, o que para Beltrán (2005) é algo essencial, pois a prática docente precisa estar aliada aos interesses, necessidades e expectativas dos alunos.

[5]

A: [...] mas também assim o fato de eles me mostrarem sempre que a língua portuguesa pra eles não é uma língua assim tão importante, embora no discurso deles, eles falam, todos repetem mesmo, tem o discurso digamos unânime de que a língua portuguesa é importante por ser língua oficial né aqui de Timor-Leste, por eles precisarem pro trabalho, mas de fato eu não acho que a língua portuguesa, o que eu observo é que a língua portuguesa não é assim tão importante pra eles [...]

[6]

B: [...] mas assim não vê sentido para aprender a língua portuguesa, 'por que que eu vou aprender a língua portuguesa, eu dou aula em bahasa, eu tenho o tétum, eu falo inglês' $[\ldots]$

Outra dificuldade era o fato dos alunos entenderem que o português era uma língua difícil de ser aprendida. Esses dois fatores (necessidade e dificuldade) acarretariam outros problemas: falta de assiduidade, pouca participação na realização das atividades extra-classe e problemas de participação em sala de aula.

Dessa forma, pode-se dizer que os desafios para o ensino de língua portuguesa no contexto de trabalho desses professores estão relacionados ao interesse do aluno pela aprendizagem da língua, pelo seu entendimento de que é uma língua difícil de ser aprendida e pelo envolvimento dos alunos nos cursos.

Além disso, os professores A e D entendiam que os alunos preferiam uma aula mais tradicional, com exposição dos conteúdos e sem muitas intervenções dos discentes, o que também era um fator que dificultaria a interação, pois reduzia a participação dos alunos. Durante as entrevistas, os professores reconheceram que houve alunos envolvidos no trabalho que foi desenvolvido, não havendo uma generalização.

Diante de todos esses desafios, os professores não esclareceram como lidaram com cada um deles em sala de aula, pois nas entrevistas não conseguiram identificar suas ações para enfrentar todas as dificuldades apresentadas. O que aparece claramente é a maneira como interviram quando houve dificuldade de entendimento de língua portuguesa por parte dos alunos.

Por outro lado, os professores conseguiram sugerir ações que auxiliariam outros professores durante o ensino de língua portuguesa, como língua não materna, em Timor-Leste 
e entre essas sugestões, está a aprendizagem de tétum (A e C), conforme é apresentado no quadro 4.

Quadro 4 - Sugestões de como lidar com os desafios.

\begin{tabular}{|l|l|}
\hline Professores & \multicolumn{1}{c|}{ Sugestões } \\
\hline A e C & É preciso estudar tétum. \\
\hline A e D & Adaptar os materias à realidade timorense. \\
\hline B e D & Utilizar diferentes materiais para o ensino. \\
\hline A & $\begin{array}{l}\text { - Não criar muitas expectativas. } \\
\text { - Conhecer as dificuldades dos alunos. } \\
\text { - Conversar com os professores antigos. } \\
\text { - Usar o ambiente fora da sala de aula em que o aluno precise utilizar o } \\
\text { português. }\end{array}$ \\
\hline B & $\begin{array}{l}\text { - Formação para os alunos sobre a importância do português. } \\
\text { - Trabalhar textos e não apenas gramática. }\end{array}$ \\
\hline C & \begin{tabular}{l} 
Pesquisar sobre a língua portuguesa em Timor-Leste \\
\hline
\end{tabular}
\end{tabular}

Fonte: Autoria própria.

Observa-se pelo quadro 4, que cada professor apresentou sugestões diferentes dependendo da problemática identificada. Entretanto, cabe observar que mesmo que o conhecimento da língua tétum para ensinar português não tenha surgido como a principal preocupação dos professores, a aprendizagem dessa língua aparece nas falas de A e C como uma sugestão para outros professores de como lidar com os desafios apresentados em sala de aula.

\section{CONSIDERAÇÕES FINAIS}

Nesta pesquisa, procurou-se investigar os principais desafios da interação durante o ensino da língua portuguesa em Timor-Leste, enfrentados por professores brasileiros. Acreditava-se, inicialmente, que o fato dos professores não terem conhecimento de tétum (língua franca) que lhes permitisse a comunicação com seus alunos seria o desafio de maior destaque na fala dos participantes.

No entanto, os professores identificaram como os principais desafios o desinteresse de alguns alunos pela aprendizagem de língua portuguesa e o seu comportamento em sala de aula (faltas, atrasados, dispersão e pouco envolvimento). Embora reconheçam que há alunos 
interessados, procurando não generalizar, os professores retomam em diversos momentos de suas falas essas problemáticas.

Nesse caso, há um reconhecimento dos participantes de que a língua portuguesa não é a língua com a qual seus alunos trabalham, pois eles utilizam o tétum, o bahasa indonésio e o inglês, mas que em algum momento, ainda não definido pelo governo timorense, terão que utilizar a língua portuguesa para lecionar suas disciplinas. Cabe ainda a reflexão de que os alunos com mais de 35 anos graduaram-se em um período em que o português havia sido proibido, o que poderia influenciar a aprendizagem, já que nessa época era comum a tortura e a repressão para aqueles que falavam português.

Dessa forma, observa-se que embora a pesquisa tenha se voltado para a questão da interação para o ensino-aprendizagem de língua portuguesa, os participantes da pesquisa demonstraram preocupação maior com o interesse e a motivação por parte de seus alunos para a aprendizagem. Assim, a falta de conhecimento de tétum ou do entendimento sobre o funcionamento dessa língua para auxiliá-los durante o ensino ficou em segundo plano.

Por outro lado, essa pesquisa permitiu verificar que o período de seis meses de trabalho ainda não é suficiente para que os professores consigam identificar as suas ações para lidar com cada desafio. Mas, possibilita estabelecer alguns critérios que permitiriam a outros professores melhorarem sua atuação, tais como: conhecimento de tétum, conhecimento da realidade timorense e da língua portuguesa no país, necessidade de uso e adaptação de diferentes materiais.

Espera-se, portanto, que este trabalho tenha contribuído para a reflexão sobre os desafios que os professores brasileiros se deparam em um contexto tão específico como é o de Timor-Leste e que as sugestões dos professores possam ser analisadas e implementadas pelo Programa para a melhoria da atuação desses profissionais.

\section{REFERÊNCIAS BIBLIOGRÁFICAS}

ALMEIDA, N. C. Língua Portuguesa em Timor-Leste. Lisboa: Lidel, 2011.

BELTRÁN, B. A. Análisis de necessidades y deseño curricular. In: Vademecum para la formación de professores - enseñar español como segunda lengua (L2)/lengua extranejra (LE). Madrid: SGEL, 2005.

BRITO, R. H. P. Temas para a compreensão do atual quadro linguístico de Timor-Leste. Ciências e Letras, Porto Alegre, n. 48, p. 175-194, jul./dez. 2010. Disponível em: 
<http://seer3.fapa.com.br/index.php/arquivos/article/view/55/50>. Acesso em: 10 jan. 2016.

CAPES. Edital do Programa de Qualificação Docente e Ensino de Língua Portuguesa no Timor-Leste. 2013. Disponível em: <http://www.capes.gov.br/cooperacao-internacional/timorleste/programa-de-qualificacao-de-docente-e-ensino-de-lingua-portuguesa-no-timor-leste>. Acesso em: 20 mar. 2016.

CORACINI, M. J. R. F. Interação e sala de aula. Calidoscópio, v. 3, n. 3. p. 199-208, set./dez. 2005. Disponível em: <http://revistas.unisinos.br/index.php/calidoscopio/article/view/6242>. Acesso em: 01 maio 2016.

FREITAS, M. T. de A. Nos textos de Bakhtin e Vygotsky um encontro possível. In: BRAIT, Beth. (Org.). Bakhtin, dialogismo e construção do sentido. Campinas, SP: Editora da UNICAMP, 1997. p. 311-328.

HULL, G. Timor-Leste: identidade, língua e política educacional. Lisboa: Instituto Camões, [s.d].

KOCH, I. G. V. A inter-ação pela linguagem. 10 ed. São Paulo: Contexto, 2006.

LÜDKE, M; ANDRÉ, M. E. D. A. Pesquisa em educação: abordagens qualitativas. São Paulo: EPU, 1986.

MOORE, M.; KEARSLEY, G. Educação a distância: uma visão integrada. São Paulo: Cengage Learning, 2011. 398 p.

MORATO, E.M. O interacionismo no campo lingüístico. In: MUSSALIM, F.; BENTES, A. C. (Org.). Introdução à lingüística: fundamentos epistemológicos. São Paulo: Cortez, 2004.p. 311-351. V. 3.

PRIMO, A. F. T. Interação mediada por computador: a comunicação e a educação a distância segundo uma perspectiva sistêmico-relacional. 2003. 292 f. Tese (Doutorado em Informática na Educação) - Universidade Federal do Rio Grande do Sul, Porto Alegre, 2003.

VYGOTSKY, L. S. A formação social da mente: o desenvolvimento dos processos psicológicos superiores. 6. ed. São Paulo: Martins Fontes, 1998. 168 p.

TIMOR-LESTE. Timor-Leste em números. Díli/Timor-Leste: Ministério das finanças. 2013. Disponível em: <http://www.statistics.gov.tl/wpcontent/uploads/2014/10/Timor_Leste_in_Figures_2013.pdf>. Acesso em: 02 mar. 2016.

Divisões administrativas. Governo de Timor-Leste. Disponível em: <http://timorleste.gov.tl/?p=91\&lang=pt $>$. Acesso em: 02 mar. 2016.

Highlights of the 2010 Census Main Results in Timor-Leste. Disponível em:

<http://www.statistics.gov.tl/wpcontent/uploads/2014/03/English_Census_Summary_2010_2.pdf>. Acesso em: 02 mar. 2016. 